\title{
BELIEF AS AN ACT OF REASON
}

\author{
NiCHOLAS KOZIOLEK \\ Washington University in St. Louis \\ Department of Philosophy \\ St. Louis-MO \\ U.S.A. \\ nkoziolek@gmail.com
}

\author{
Article info \\ CDD: 121 \\ Received: 25.06.2018; Accepted: 10.09.2018 \\ DOI: http://dx.doi.org/10.1590/0100-6045.2018.V41N4.NK
}

\section{Keywords: \\ Belief \\ Doxastic Agency \\ Ontology of Belief}

\begin{abstract}
Most philosophers assume (often without argument) that belief is a mental state. Call their view the orthodoxy. In a pair of recent papers, Matthew Boyle has argued that the orthodoxy is mistaken: belief is not a state but (as I like to put it) an act of reason. I argue here that at least part of his disagreement with the orthodoxy rests on an equivocation. For to say that belief is an act of reason might mean either (i) that it's an actualization of its subject's rational capacities or (ii) that it's a rational activity (hence, a certain kind of event). And, though belief is not an act of reason in the second sense, it may nonetheless be one in the first: it may be a static actualization of its subject's rational capacities.
\end{abstract}

Acknowledgments: I presented material related to this essay at a 2017 meeting of the Auburn University Philosophical Society, at the 2017 meeting of the Alabama Philosophical Society, and at the 2017 meeting of the Canadian Society for Epistemology. I'm grateful to all three audiences for their questions, objections, and suggestions. 
I'd also like to thank both Jeremy Fix and Andy Werner for helpful comments on the penultimate draft.

\section{INTRODUCTION}

According to Matthew Boyle, "for a rational subject to believe something is for him to have his power to be persuaded by reasons actualized in a present and persisting $a c t^{\prime \prime}$ (2011: 22, my emphasis). In taking this view—that, as I'll put it, belief is an act of reason Boyle places himself in stark opposition to the orthodoxy, i.e., the widespread view that belief is not an act but a state, and that, therefore, a subject's power to be persuaded by reasons is actualized, not in her believing what she does, but, instead, in (and only in) her judging what she does-where, at least when all goes well, her so judging results in appropriate changes to her beliefs. On this view, belief is not an act of reason, but is, instead, merely the effect of one. And so, it seems, we have a choice: either belief is a state or it is an act of reason. ${ }^{1}$

I want to suggest, however, that there's a third option: that belief is both a state and an act of reason. To that end, I have two aims in this essay. The first is clarificatory: I want to distinguish two different things it might mean to say that belief is an act of reason-or, more specifically, that it's an act. For this might mean, first, that belief is an actualization of its subject's rational capacities. Or it might mean, second,

\footnotetext{
1 The orthodoxy, or something like it, is expressed or defended by, e.g., Broome (2013: 77-78), Cassam (2010), Lee (2018), McHugh (2011, 2013), O’Shaughnessy (2000: 106), Owens (2000: 87), Peacocke (1998), Shah and Velleman (2005), Shoemaker (2009), Soteriou (2005), and Toribio (2011). Boyle develops his heterodox view primarily in his 2009 and 2011, though his 2015 is also relevant; similar views are taken by, e.g., Hieronymi (2006, 2009), and Korsgaard (2009).
} 
that belief is a rational activity (in what I will call the temporalmetaphysical sense). Boyle's view seems to be that belief is an act of reason in both of these senses: it is an actualization of its subject's rational capacities (her "power to be persuaded by reasons") that is also an activity ("a present and persisting act") of hers. The orthodox view, by contrast, seems to be that belief is an act of reason in neither of these senses: simply put, belief is a state, and no state is an act, so belief is not an act of reason. The importance of distinguishing these two claims - that belief is an actualization of its subject's rational capacities and that it's an activity - thus lies in the fact that doing so reveals additional theoretical possibilities: for belief could be an act of reason in one but not both of these senses.

My second aim is critical: I will argue that belief is not an act of reason in the second sense. I will argue, in other words, that belief is not an activity. To say this, however, is not simply to side with the orthodoxy. For the orthodoxy remains deficient in failing to see that belief $i$, nonetheless, an act of reason, in the sense that it's an actualization of its subject's rational capacities - and not, as the orthodoxy would have it, merely the effect of one. On my view, then, the fundamental insight toward which Boyle points us is that belief is an actualization of its subject's rational capacities, and so belongs, and belongs essentially, to the faculty of reason; whereas, for all the orthodoxy says, it could be related to reason only per accidens. But this insight, at least, is independent of the highly questionable heterodox claim that belief is not a state- a fact that, at the very least, Boyle's own discussion tends to obscure.

My overall aim here is thus to clarify the nature of the insight that seems to me to be present (though obscured) in Boyle's writings. As a consequence, the orthodoxy itself will receive rather short shrift. In effect, I'll be confining myself to asserting — as I already have — that the orthodoxy fails to acknowledge the fact that belief is an act of reason, in the sense that it's an actualization of its subject's rational 
capacities. For reasons both of space and of thematic unity, I'll leave the defense of that claim for another occasion. With respect to the orthodoxy, then, the only thing I will show here is that it doesn't follow from the fact that belief is an actualization of its subject's rational capacities (hence, from the fact that it's an act of reason in that sense) that it isn't a state - a point that, in itself, is friendly to the orthodoxy.

\section{AGENCY AND RESPONSIBILITY}

I want to begin, however, with some remarks concerning some of the background to the debate described in section 1. As I've characterized Boyle's dispute with the orthodoxy, it turns on the question whether belief is an act of reason. Importantly, however, Boyle himself characterizes the dispute in slightly different terms. On his characterization, the dispute turns, not on the question whether belief is an act of reason, but, instead, on the apparently distinct question whether it is an exercise of rational agency. He thus represents his central aim as that of calling into question "certain natural but unwarranted assumptions about the structure of rational agency" (2011: 3, my emphasis). What this means is that there are really three different claims at issue here:

(i) that belief is an actualization of its subject's rational capacities,

(ii) that belief is a rational activity,

and

(iii) that belief is an exercise of rational agency.

And so there are really three different things it might mean to say that belief is an act of reason. 
For my purposes here, what's important about this third claim - that belief is an exercise of rational agency - is that, at least on the face of it, it's incompatible with the view that belief is a state, for the simple reason that no state can be an exercise of agency. ${ }^{2}$ As such, it's central to the larger conflict between Boyle and the orthodoxy, which resides primarily in the fact that the following four claims are jointly inconsistent:

(a) Belief is a state.

(b) We are directly responsible for our beliefs.

(c) We can be directly responsible for our beliefs only if they are themselves exercises of our rational agency.

(d) No state can be an exercise of agency.

The crucial point is that, if claims (b), (c), and (d) are all true, then claim (a) is false: belief is not a state. The orthodox way of resolving this inconsistency is to reject claim (b), by retreating to the view that we are only indirectly responsible

2 Cf. Boyle (2011: 4): “All [i.e., Peacocke (1998: 88), Shah and Velleman (2005: 503), and Cassam (2010: 82-83)] assume that an exercise of agency [... ] must be an occurrent event or process. Belief, however, they take to be a standing state, not an occurrent event or process. Hence, all of these authors conclude, believing that things are thus-and-so cannot itself be an exercise of agency." Boyle does reject the assumption that an exercise of an agency must be an occurrent event or process. But, as I'll explain below, he doesn't do so by allowing that an exercise of agency can be a state. Instead, he does so by arguing that his opponents overlook a fourth possibility, namely, (as I've been putting it) that belief is an activity - where an activity, unlike a state, can be an exercise of agency. 
for our beliefs. Boyle suggests, however, that this conclusion isn't forced on us, because it's also open to us to reject claim (a), by taking the view that belief is an activity, rather than a state. ${ }^{3}$ The view that belief is an activity thus provides a potential way of vindicating the claim that we're directly responsible for our beliefs.

I'll be arguing in section 3, however, that belief is not an activity. One consequence of my argument there is thus that Boyle has not yet managed to vindicate the claim that we're directly responsible for our beliefs, because he has not yet managed to make plausible the view that belief is not a state. To do that, he needs to show that there's a plausible alternative; and, so far, he has not. In consolation, however, I offer section 5, in which I argue that it doesn't follow from the fact that belief is a state that it isn't an actualization of its subject's rational capacities - and in which I then sketch a theory of belief on which it is exactly that. The latter theory, as I've said, at least goes beyond the orthodoxy, by acknowledging that there's a sense in which belief is an act of reason. It also seems to capture at least part of what Boyle himself is going for in saying that "for a rational subject to believe something is for him to have his power to be persuaded by reasons actualized in a present and persisting act" (2011: 22, my emphases).

What the theory I offer in section 5 doesn't do, however, is vindicate the claim that we're directly responsible for our beliefs. And it might seem that, on the issue of responsibility, at least, I'm giving Boyle insufficient credit here, by ignoring some of the things he has to say about the nature of rational agency. ${ }^{4}$ For his view seems to be that an exercise of rational agency is, quite simply, an actualization of a special kind of

${ }^{3}$ See, e.g., Boyle (2011: 4, 6).

${ }^{4}$ I'm grateful to an anonymous referee for Manuscrito for pressing me to say more about this issue here. 
rational capacity, namely, an active one (as opposed to a passive one). And, on that view, in order to vindicate the claim that we're directly responsible for our beliefs, we need only show that belief is an actualization of its subject's active rational capacities - something that (it might then be argued) Boyle plausibly has done.

This sort of view does, I think, represent an interesting strategy for defending the claim that we're directly responsible for our beliefs. ${ }^{5}$ But, in the present context, it's ultimately irrelevant. Given Boyle's dispute with the orthodoxy - in particular, his apparent denial that belief is a state-we need to ask: can a state be an actualization of its subject's active rational capacities? The natural answer, in the present context, is that it can't: just as no state can be an exercise of agency, no state can be an actualization of an active capacity. But, in that case, in order to vindicate the claim that we're directly responsible for our beliefs, you'd need to show that there's a plausible alternative to the view that belief is a state-and so we're right back where we

${ }^{5}$ I don't myself think that it can work, because I don't think that active capacities generally, or even active rational capacities more specifically, are agentive in a sense that can ground responsibility. But I'll leave that issue for another day. Here, I'll just add that, on the question of our responsibility for our beliefs, I'm inclined to side with the orthodoxy and retreat to the claim that we're only indirectly responsible for our beliefs. So, although the view I develop in section 5 falls short of vindicating that claim that we're directly responsible for our beliefs, and may even (for all I can tell) be incompatible with it, that doesn't strike me as a defect-for it was no part of my aim to vindicate that claim. Those sympathetic to Boyle's view might thus find my view disappointing, but my central objection stands: Boyle has so far given us no viable alternative to the orthodox view that belief is a state. Unless he can do so, it seems to me that there's good reason to prefer my view to hiseven if that means giving up on the claim that we're directly responsible for our beliefs. 
started. On the other hand, if the answer is that a state can be an actualization of an active capacity-if, in effect, Boyle is working with a special conception of rational agency, on which a state can be an exercise of rational agency (and so on which claim (d) is false) — then he's just granted my central contention, i.e., that belief can be both a state and an actualization of its subject's rational capacities. In this case, of course, Boyle's discussion of the nature of rational agency does provide a possible way of vindicating the claim that we're directly responsible for our beliefs. But it does so, not by rejecting my conclusions, but by combining Boyle's conception of rational agency with (something like) my view of belief as a static (stative) actualization of its subject's rational capacities.

For the remainder of this essay, then, I'll be setting the issues of responsibility and agency aside. What I want to show is, more simply, that Boyle has not yet shown that there's a plausible alternative to the view that belief is a state. He thus has two options: either bring such an alternative into view (and so overcome the obstacles I'll be describing in section 4), or admit that belief is a state after all, and draw the relevant consequences for the rest of his view, whatever they may be.

\section{IS BELIEF AN ACTIVITY?}

What we've seen, then, is that, in an attempt to vindicate the claim that we're directly responsible for our beliefs, Boyle suggests that belief may be an activity, rather than a state. But what is an activity? And is belief really one of them? My aim in this section is to show that, on Boyle's own account of what an activity is (which I think is correct, as far as it goes), belief is not an activity.

Boyle begins his presentation of his own positive view with a discussion of some ideas of Aristotle's. The basic 
Aristotelian framework he introduces here hinges on two distinctions: first, between a capacity and its actualization; and, second, between a kinesis and an energeia-or, in the terminology I'll be employing here, between a process and an activity. As Boyle notes (2011: 19-20), these two distinctions converge in the claim that a capacity can be actualized either in a process or in an activity-or, indeed, in an "occurrent event" (cf. Boyle 2011: 4). But since the question in the present section is just whether belief is an activity, I'll begin by considering the second distinction in isolation, ignoring the fact that capacities can be actualized in various different ways. That fact will, however, be important later (especially in section 5).

As Boyle explains it, the basic distinction between a process (kinesis) and an activity (energeia) is that the former, but not the latter, is a kind of change that is "characterized by a certain 'incompleteness"' (2011: 19). Thus, "while a kinesis is occurring, the relevant change has not yet reached the result towards which it is proceeding, and when the result is reached, the kinesis itself is no longer extant" (2011: 19-20). An activity, by contrast, "does not consist in the unfolding of a process proceeding towards a certain result, but rather in a mode of active being, every moment of whose existence constitutes a moment of the completion of the activity" (2011: 20, his emphases). As I'll explain in more detail in section 4 , this distinction is marked linguistically by the contrast between progressive and (merely) ${ }^{6}$ imperfective aspect: the sentence "I was walking to the store"-which indicates "the result towards which" the event is "proceeding" (namely, my arrival at the store), and so describes a process or kinesis - has progressive meaning; whereas the sentence "I was walking" (with no destination in mind, as in "I was taking a stroll")—which indicates no

6 I say "merely" here because, as I explain in section 4, the progressive is itself a form of the imperfective. 
prospective result and is "complete at every moment of [its] occurrence" (Boyle 2011: 20), and so describes an activity or energeia-has (merely) imperfective meaning. In these terms, the "completeness" of an activity is indicated by the fact that the (non-progressive) imperfective description of an event entails a corresponding description of the event with perfective aspectual meaning: if you were walking, then you walked (for some amount of time). It is in this sense that an activity is "complete at every moment": schematically, where $\varphi$ ing is an activity, to have begun to $\varphi$ is to have $\varphi$ ed. The corresponding "incompleteness" of a process is then indicated, correlatively, by the fact that the progressive description of an event does not entail a corresponding perfective one: the fact that you were walking to the store doesn't entail that you walked to the store, for you may never have reached the store. A process is thus not complete at every moment, but instead remains incomplete until it reaches the result towards which it is proceeding: schematically, where $\varphi$ ing is a process, to have begun to $\varphi$ is not necessarily to have ped.

An initial obstacle to Boyle's claim that belief is an activity, then, is that it isn't describable in the imperfective aspect-certainly not naturally. Thus, we don't usually (if ever) say of people that they "are/were believing" things. ${ }^{7}$ In fact, it's not easy to make sense of such an idiom, even on a generous interpretation. For example, what could it possibly mean to say "While I was believing that today was Friday, I fried an egg"? Boyle suggests, however, that this objection involves a conception of activities that models them too closely on intentional actions. He thus stresses that, on his view, there is an important difference between the kind of activity an intentional action is and the kind of activity a

7 This point is made by Cassam (2010: 81), who also cites Williamson (2000: 35). Boyle mentions the point (2011: 6), but, curiously, never responds to it directly. 
belief is. As he explains it in one place: "[a]n ongoing intentional action is an activity in progress, whereas a persisting belief is, we might say, an activity in stasis" (2009: 141, his emphases). He also explains that, as he understands it, the "act" of believing "is not occurrent-it need not involve any bustle or commotion, whether in the subject's consciousness or elsewhere" (2009: 143-144). So perhaps we just need a better understanding of the nature of an "activity in stasis." The phrase itself (the noun 'activity' modified by the adjectival phrase 'in stasis') suggests that we're dealing with a special kind of activity-one that, presumably, is difficult to recognize as such (otherwise we wouldn't be so tempted to think that belief is a state, rather than an activity in stasis). But what kind?

The most obvious answer, I think, is that an activity in stasis is an activity that doesn't essentially involve any change-any "bustle or commotion," as Boyle puts it. Indeed, Boyle himself notes that Aristotle's term 'kinesis' is frequently translated as 'change', and he describes an energeia (i.e., an activity), by contrast, as "a mode of active being" (2011: 20, his emphasis). One interesting thing about the suggestion that an activity in stasis is one that doesn't essentially involve any change is that there are actually intentional actions that seem to be activities in stasis in the resulting sense. ${ }^{8}$ Holding a glass of whisky, for example, doesn't seem essentially to involve anything's changing, any "bustle or commotion": you could just be standing there, totally still, holding the glass of whisky, your mind empty. Nonetheless, it does seem to be an activity (and an intentional action). At least, it's

${ }^{8}$ I don't think that this fact undermines Boyle's response to the above objection. His point, as I'm reading him, is that paradigmatic intentional actions are activities in progress, and it's a mistake to assume that all activities need to be like these paradigmatic intentional actions - for there are also activities (including nonparadigmatic intentional actions) in stasis. 
definitely describable in the imperfective, and the imperfective description entails a corresponding perfective one: if you were holding a glass of whisky, then you beld a glass of whisky, for some amount of time. It is thus, as Boyle says, "complete at every moment." Examples like this one serve to show that there are activities in stasis, at least in the sense that there are activities that don't essentially involve any change. Of course, since some of them are intentional actions, we can't say, as Boyle does, that intentional actions as such are activities in progress rather than activities in stasis. But we still have a comprehensible proposal on the table, namely, that belief is an activity that doesn't essentially involve any change.

But is belief really an activity in stasis in this sense? True, it doesn't essentially involve any change. But, then, neither does any state (cf. section 4). And while Boyle, in presenting his positive view, makes frequent use of the idiom of "holding a belief" (cf. Boyle 2011: 21, note 33), "holding a belief"-i.e., believing - just doesn't seem to be the same kind of thing as holding a glass of whisky. ${ }^{9}$ Indeed, the fact that we don't describe belief in the imperfective is, I will argue, a reflection - a symptom-of our awareness of this underlying difference (see section 4.4). So we can't do what Boyle seems to suggest we do, namely, understand the sense in which belief is an activity by starting with paradigmatic intentional actions-activities in progress - and then imagining a similar kind of thing, only in stasis rather than in progress. What we get when we do so does seem to describe some things, for example, the activity of holding a glass of

9 Of course, we do sometimes talk of "believing," and do so quite naturally — as, in fact, I just did in the text. But this kind of abstract noun (or, in other cases, noun phrase) doesn't have imperfective meaning, and is not non-stative. Hence, we talk in the same way, and just as naturally, of such things as being red. But being red is not an activity — not even an activity in stasis. 
whisky. But there are important differences between believing ("holding a belief") and holding a glass of whisky. And we won't understand the claim that belief is an activity until we understand that difference, and its compatibility with the claim that belief, too, is an activity. (The other way of going here is of course to say that the difference consists in the fact that belief is a state, while holding a glass of whisky is an activity. But Boyle is precisely rejecting this explanation of the difference.)

There are, I think, other things it might mean to say that belief is an activity, or that it is "a mode of active being," or, more simply, that it is "active," as Boyle also says (2009: 121). One, which I've already mentioned, and will return to below, is that it is an actualization of its subject's rational capacities. Another, which is closely related, is that it is an actualization of an active capacity. Boyle himself occasionally says things that are suggestive of both of these views, for example when he says that someone's "believing something on a certain basis is itself an active condition, the energeia of an active capacity to determine what he believes by assessing the grounds for holding a given belief' (2011: 21, my emphasis). ${ }^{10}$ The problem with these suggestions, however, is that neither of them provides us with a plausible alternative

10 Note that, in this passage, Boyle apparently uses the word 'energeia' to mean "actualization of a capacity," rather than-or, perhaps, in addition to- "activity." The result is that, in this particular passage, he seems to be claiming that belief is "active" in all of the following three senses: (i) it is an actualization of its subject's rational capacities; (ii) it is an activity; and (iii) it is an actualization of an active capacity. Indeed, since, as we saw in section 2, his claim here is made in the service of the claim that belief is an exercise of rational agency, there are actually four distinct senses in which he is here suggesting that belief is "active" (though, as we also saw in section 2, it may be that, on Boyle's view, the claim that belief is an exercise of rational agency is merely a terminological variant of claim (iii)). 
to the view that belief is a state. For, as I'll argue in section 5 , belief could be both a state and an actualization of its subject's rational capacities-and I don't myself see why the capacities in question couldn't be active (though I won't address that issue here)..$^{11}$ Moreover, neither of these senses in which belief might be said to be "active" seems to mark the kind of contrast with processes that is central to the distinction between kinesis and energeia. (Nor, importantly, does the claim that belief is an exercise of rational agency, since a kinesis, too, can clearly be an exercise of agency: witness intentional actions.) In other words, the claim of Boyle's that I'm targeting here is the claim that belief is neither a state nor a process nor an "occurrent event," but is, instead, an activity. As far as I can see, however, capacities, including active ones, can be actualized in any of these ways. And, indeed, when it comes to processes, activities, and "occurrent events," at least, that was part of Boyle's own point: he introduces kinesis and energeia as "two kinds of actualization of a capacity" (2011: 19). Hence, what we're looking for is a sense in which belief could be said to be an activity, where that contrasts with the claim that it's a state, process, or "occurrent event." So far, we've failed to identify any such sense. Of course, that failure could be for simple lack of imagination. I'll argue in the next section, however, that it's not.

\section{STATES, PROCESSES, ACTIVITIES, AND ACTS}

My aim in this section is to provide a clearer picture of what exactly is involved in denying that belief is a state, by providing a systematic presentation of what I take to be all

${ }^{11}$ Cf. note 5 above. I plan to address the distinction between active and passive capacities, and its bearing on the nature of belief, in future work. 
of the available options. To that end, I'll argue that belief must belong to one of only four temporal-metaphysical categories — states, processes, activities, and acts. ${ }^{12}$ Given these options, I think it's clear that belief must be a state. The challenge for the kind of heterodox view proposed by Boyle_-on which belief is not a state-is thus to show both that there are additional temporal-metaphysical categories and that belief belongs to one of them. (This section is thus intended primarily for readers who are not yet persuaded that belief is a state- either because they are not yet persuaded that it is not an activity, or because they think that there must be some other option. ${ }^{13}$ Readers who are persuaded that belief is a state might want to skip ahead to section 5.)

States, processes, activities, and acts-as I will understand them here-belong to distinct temporalmetaphysical categories. The domain of temporalmetaphysical categories - of what are sometimes called situations - divides into (i) the static and the dynamic, (ii) the telic

${ }^{12}$ I use the word "act" here in what I call its temporal-metaphysical sense. As we've seen, the same word is sometimes used to mean "activity," "actualization," and "exercise of agency"—and Boyle, for his part, uses it in all three ways. I will avoid the latter three uses myself, with one exception, namely, in the phrase "act of reason," where the ambiguity is precisely the point.

${ }^{13}$ One philosopher who seems to fall into the latter camp is Rödl (2007: 72-79), who argues that belief is not a state, but is (I think) nonetheless skeptical of Boyle's view that it is an activity (see, in particular, Rödl 2018: 35-36). I don't find Rödl's arguments persuasive (though they raise some interesting and important issues), and they're complicated enough that I can't discuss them here, but I think it's important to acknowledge the possibility of a view on which belief is neither a state nor an activity, but something else entirely. Hence my inclusion of the present section - which might otherwise seem like overkill. (I'm indebted here to discussion with Andy Werner.) 
and the atelic, and (iii) the durative and the punctual. ${ }^{14}$ The resulting classification is illustrated in Figure 1.

Figure 1: temporal-metaphysical categories

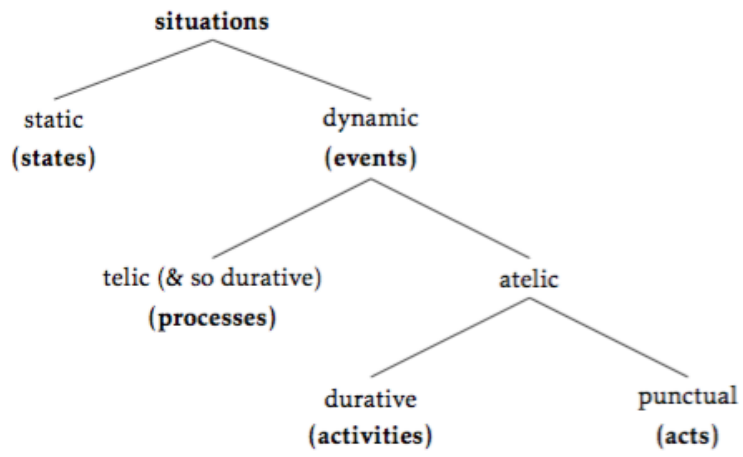

14 For these distinctions, see Comrie (1976: Chapter 2). Comrie is of course a linguist, not a metaphysician. But, in my view, his discussion nonetheless provides an excellent guide to the basic metaphysical distinctions at issue here. In any case, the view I develop below is similar to the view taken by Mourelatos (1978), though his terminology is importantly different: in particular, what I call activities he calls processes, and what I call processes he calls developments (in my terminological choices, I'm instead following Boyle). It is also broadly in line with Steward (1997). The literature on these issues is now quite large-indeed, Mourelatos himself was generalizing and correcting ideas developed by Vendler (1957) and Kenny (1963), who were, in their turn, working out ideas introduced by Ryle (1949) — and I don't claim to do justice to all of the complexities it reveals. I do, however, think that the view I develop below can be elaborated in a way that will allow it to handle those complexities; I just won't try to defend that claim here. 
As the figure shows, a state is simply a static situation. Processes, activities, and acts are all dynamic situations, which I also call events. Processes are both telic and (as a consequence) durative. Activities are also durative, but are atelic rather than telic. Acts, by contrast, are punctual, and are, as a consequence, atelic (a point that I'll explain in due course; cf. note 18 below). I'll explain these distinctions in detail in section 4.1-4.3. In section 4.4, I'll then argue, again (though very briefly), that, at least if these are the options, belief is a state-which means that, in order to show that belief is not a state, you'd need to identify additional temporal-metaphysical categories.

\subsection{THE STATIC AND THE DYNAMIC}

The distinction between static and dynamic situations-or, as I'll also say, between states and events - is notoriously difficult to draw precisely. As I understand it, though, the basic idea is that dynamic situations, or events, are intrinsically related to time, and are therefore intrinsically temporal situations; while static situations, or states, are only extrinsically related to time (when they are related to time at all), and so are intrinsically atemporal situations. More metaphorically, we can also say that an event is something that happens in time, while a state is something that merely obtains at a time (cf. Steward 1997: 72ff.). The distinction between states and events is marked in language (more or less explicitly, depending on the language in question) by the fact that event-descriptions are aspectual, while state-descriptions are not. More precisely, event-descriptions are either in the imperfective aspect, as in " $x$ was $\varphi$ ing," or in the perfective aspect, as in " $x$ yed." Roughly speaking, each of these descriptions takes a different perspective on the event described: the former views it, as it were, from within, as something ongoing; whereas the latter views it from without, as a 
completed whole (cf. Comrie 1976: 16ff.). State-descriptions, by contrast, are neither in the imperfective nor in the perfective aspect, but are (again) wholly non-aspectual. Thus, walking is an event: " $x$ was walking" and " $x$ walked" are both event-descriptions, the former imperfective, the latter perfective. Being red, by contrast, is a state: “ $x$ was red," which is non-aspectual (and hence is neither perfective nor imperfective), is a state-description. Both event-descriptions and state-descriptions can be tensed, and thus can relate the described situation differently to the time of the description, as being either past, present, or future. Tensed descriptions relate the described situation to a particular time-normally, that of the description itself-only externally or extrinsically. ${ }^{15}$ Aspectual descriptions, however, characterize the internal or intrinsic temporality of the described situation itself-its temporal shape, as Helen Steward (1997: 97-101) has called it.

The latter points are, of course, about our descriptions of situations, and not about the situations themselves. We can transfer them from the former to the latter, however, by saying that dynamic, but not static, situations (events, but not states) are correctly describable aspectually. The difficult question, in any particular case, will then be whether a given situation is in fact correctly describable aspectually_-which means that our question will be whether belief is correctly describable aspectually. I will return to this question momentarily. First, however, it will be best to treat of the distinctions between the three different categories of event—processes, activities, and acts—because doing so will help to clarify the aspectual nature of event-descriptions, and thereby the intrinsic temporal shapes of events themselves. We will then be in a better position to ask whether belief has any of those temporal shapes.

15 On the relation between aspect and tense, see Comrie (1976: chapter 4). 


\subsection{THE TELIC AND THE ATELIC}

Dynamic situations, or events, can be divided into the telic and the atelic, i.e., into those that have ends (in the sense of "things towards which they are proceeding"—an idea familiar from section 3) and those that do not. Telic events (and telic events alone)—which I will call processes-are describable in the progressive, as in I was walking to the store, where it is possible for it to be true that I was walking to the store, but never that I walked to the store-because, for whatever reason, I never reached the store. Atelic events, by contrast, are not describable in the progressive, but some of them-the durative ones, which I will call activities-are nonetheless describable in the (non-progressive) imperfective, as in I was walking (with no destination in mind, as in "I was taking a stroll"). ${ }^{16}$ Here, there is no possibility of the event's failing to reach its end, as in the case of a telic event-not because it is somehow guaranteed to reach its end, or because it has always already reached it, but because it has no end. ${ }^{17}$ Atelic events are thus generally marked by the

16 As this example suggests, it will sometimes be possible to describe the same situation, the same event, in either telic or atelic terms. In particular, many processes can also be described in atelic terms (walking to the store, for example). It is thus important that an activity, as I have explained it, is an event that cannot be described in telic terms; that is what makes it atelic. Thus, walking to the store, for example, is, in itself, essentially telic, although it can always be described atelically, by omitting the reference to its end. Equally, all movement is telic, and so a process, because it is correctly describable as a movement from one place to another.

${ }^{17}$ Boyle, I should mention, follows Aristotle in saying that " $[a] n$ energeia [i.e., an activity] is an actualization of a capacity in which the end is present" (2011: 20, my emphasis; the embedded quote is from Aristotle's Metaphysics, IX.6, 1048b22). This characterization of energeia suggests that, on Boyle's and Aristotle's view, activities (like processes) are telic. I think, however, that there are actually 
validity of the inference from the imperfective to the perfective: if I was walking, then I walked (for some amount of time). Telic events, correlatively, are marked by the invalidity of the inference from the progressive (a form of the imperfective) to the perfective: it doesn't follow from the fact that I was walking to the store that I (ever) walked to the store. ${ }^{18}$

\subsection{THE DURATIVE AND THE PUNCTUAL}

Finally, events can also be divided into the durative and the punctual. Durative events are those with intrinsic temporal parts, hence those that essentially take time. Punctual events, by contrast, are those without intrinsic temporal parts, hence those that do not essentially take time. To have intrinsic temporal parts, in the relevant sense, is to be describable in the imperfective (which, again, includes the progressive as a species), which allows for the location of other events as occurring within the time of the event so described, as in "While I was walking (to the store), I saw an eastern bluebird." Thus, processes and activities are both durative, since they are both describable in the imperfective. Punctual

two different senses of "end" in play here: (i) end in the sense of "that towards which" and (ii) end in the sense of "that for the sake of which." It is (i) that I employ, in the text, to draw the telic/atelic, process/activity distinction. But it is (ii) that is employed in Aristotle's claim that "the end is present."

18 Note that, by this criterion, punctual events (which I explain immediately below, in section 4.3) vacuously pass the test for atelicity: because they are not describable in the imperfective at all, it is vacuously true of them that descriptions of them in the imperfective entail corresponding descriptions of them in the perfective. Nothing really hangs on this point, but it explains the classification of events that I gave in Figure 1. 
events-which I will call acts-on the other hand, lack intrinsic temporal parts, and so are not describable in the imperfective. They are, however, describable in the perfective (which distinguishes them from states that obtain only for an instant, and, indeed, from any lasting state's obtaining at some given instant-thus, a punctual event is not merely a state conceived as obtaining at an instant, but is something else entirely). This means, of course, that punctual events are describable only in the perfective ${ }^{19}$ - hence the absurdity of saying things like "While I was noticing that the light was red, I lit my cigarette" (which may usefully be contrasted with "While I was lighting my cigarette, I noticed that the light was red"). Noticing that the light is red is thus an example of a punctual event, i.e., an act. It is, in the metaphorical way of speaking introduced earlier, something that (unlike a state) happens in time but that (unlike a durative event) does not essentially take time. (States, we might say, neither take time nor happen in it, but instead obtain alongside it.)

It's important to notice that, while punctual events don't essentially (and so don't necessarily) take time, there is a sense in which they may nonetheless take time-though only accidentally (or contingently). ${ }^{20}$ It's plausible, for example, that the act of noticing (e.g., that the light is red) is realized by neurological processes that, as processes, do essentially take time. From this it may seem to follow that the supposedly

\footnotetext{
${ }^{19}$ Interestingly, Comrie (1976: 43-44) reports that, in both Russian and Hungarian, there are classes of verbs that, grammatically, take only perfective, and never imperfective, aspect. There are no such verbs in English because the perfective/imperfective distinction isn't grammaticalized in English; cf. Comrie (1976: 7).

20 Similar points will apply to states, which - in the terminology I use below-may be realized by events without thereby being made up of them. For this reason, the fact that states can be (and perhaps always are) realized by events doesn't obliterate the distinction between states and events.
} 
punctual act of noticing isn't punctual after all. But it doesn't. Even granting the neurological story, it remains that the act of noticing isn't essentially realized by neurological processes — or, indeed, by anything at all. ${ }^{21}$ And if we ignore the realizer of the act, and its temporal-metaphysical category, there will no longer be any ground for ascribing to the act of noticing any duration whatsoever. So, if we distinguish between an event and its realizer, we can say that a punctual event is one that, if it can be said to have duration at all, can be so described only in virtue of being realized by a durative event. A durative event, by contrast, is one that can be said to have duration, not merely in virtue of being realized by a durative event, but, instead, in virtue of itself. Processes and activities are both durative in themselves, because (or so I would argue) they are both essentially made up of processes - which are themselves essentially made up of processes...that are essentially made up of acts. Acts themselves, however, are not, in this sense, (either essentially or accidentally) made up of anything. (I think it's instructive, here, to compare acts and processes, respectively, to points and lines.)

\subsection{BELIEF IS A STATE, NOT AN EVENT}

In these terms, then, the claim that belief is an activity is to be understood as the claim that it is a durative atelic dynamic situation. One resulting problem for the view that belief is

\footnotetext{
21 More carefully: even if the act of noticing must be realized by processes of some kind (and so is necessarily realized), the explanation of this fact won't advert merely to the essential nature of this act itself; instead, it will have to appeal to general facts about, for example, the impossibility of (say) mental acts that aren't realized by physical processes of some kind or other. My appeal to the essence of the act is thus essential here.
} 
an activity-which we already encountered in section 3-is that it isn't describable aspectually, as events are. We can now, however, say a bit more about the metaphysical significance of that fact. For, if what I said in section 4.3 is correct, then, if believing were an activity, it would essentially have temporal parts, and so would have to be made up of processes (and ultimately of acts) of some kind - just as, say, smoking a cigarette is made up of the processes of taking a drag, exhaling, tapping off some ash, and so on. Believing, however, doesn't seem to have temporal parts in this sense. In this respect, at least, believing something seems to be just like, say, being red. Both of these states can persist over a period of time. But neither of them occurs in time in the way an event does. It is this fact about belief, I suggest, that ultimately underlies the oddity of saying such things as "While I was believing...": the latter implicitly asks us to look for the events that make up the activity of believing-and, it would seem, there are none. It follows immediately that belief is not a durative event, and so is neither an activity nor a process. But it's clearly not an act, either; for one thing, it can persist through time in a way in which an act can't. So, if belief were an act, believing something for an extended period of time would have to consist in the ceaseless repetition of the act of believing-something it certainly doesn't seem to do. It follows, then, that belief is a statejust as the orthodoxy claims.

More cautiously, though, what I really want to suggest here is that, in order to show that belief is not a state, you'd need to show that there are additional temporal-metaphysical categories, categories beyond states, processes, activities, and acts. To do that, though, you'd need to show that the distinctions discussed here-between the static and the dynamic, the telic and the atelic, and the durative and the punctual-don't suffice to characterize all of the ways in which situations can differ in their respective relations to time. In fact, since the foregoing strongly suggests that belief 
isn't a dynamic situation-isn't an event of any kind-you'd need to show that the distinction between the static and the dynamic is really only part of a threefold distinction between the static, the dynamic, and some third category of situation that is neither static nor dynamic. Perhaps there is such a category. But, if there is, its existence has yet to be demonstrated. And, for my own part, I don't see what this third category of situation could possibly be. Opponents of the view that belief is a state thus seem to me to have their work cut out for them.

\section{BELIEF AS AN ACT(UALIZATION) OF REASON}

My aim in this final section is to show that Boyle is nonetheless onto something when he claims that, as I've put it, belief is an act of reason. More precisely, my aim is to show that it doesn't follow from the fact that belief is a state that it isn't an act of reason-in one important sense of the phrase, anyway - because it doesn't follow from the fact that belief is a state that it isn't an actualization of its subject's rational capacities. For there are states that are the actualizations-the static actualizations, we might say-of other rational capacities. So maybe belief, too, is the static actualization of a rational capacity. Thus, in section 5.1, I'll explain the distinctive nature of these static actualizations of rational capacities. Then, in section 5.2, I'll very briefly sketch an account of belief on which it's one of them. ${ }^{22}$

${ }^{22}$ For further elaboration of the view sketched there, see Koziolek (2017) and, especially, Koziolek (MS). 


\subsection{STATIC ACTUALIZATIONS OF RATIONAL CAPACITIES}

So, finally: are there actualizations of rational capacities that are states? And is belief one of them?

The answer to the first question is that there are-at least in a qualified sense. The conception of a capacity and its actualizations that establishes this answer is one that is originally due to Aristotle, and has been important to the Aristotelian tradition. ${ }^{23}$ On this conception, there are some capacities that have, in effect, a tiered structure, where the capacity is first actualized in what is itself a second capacity that can be further actualized in an event (process, activity, or act) of the kind that the capacity, as a whole, is a capacity for.

A well-known example is the capacity to speak French. The first thing to notice here is that there are two distinct senses in which someone might be said to be capable of speaking French. For there is, first, the sense in which the adult native French-speaker is capable of speaking French: she knows French, and so can, simply, speak it, should an appropriate occasion arise. But there is also, second, the sense in which an infant is capable of speaking French: she is capable of learning it. The Aristotelian view is that these two capacities - the capacity to speak. French and the capacity to learn French-are not independent capacities, but are instead intimately related "components" of a single capacity, which we might describe as the capacity (to learn) to speak French. The unity of the two capacities in one "tiered" capacity is a reflection of the fact that an account of the capacity to learn French will make essential reference to the actualization of the capacity to speak French. For, in general, a capacity is defined in terms of its actualization. The actualization of the capacity to learn French, however, is itself a capacity: the capacity to speak French. So it will ultimately be defined in

${ }^{23}$ In what follows, I'm drawing on Kosman (2013). 
terms of the actualization of the latter capacity, hence, in terms of the activity of speaking French.

\section{Figure 2: the capacity (to learn) to speak French}

\section{the capacity to learn French}

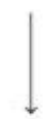

the capacity to speak French

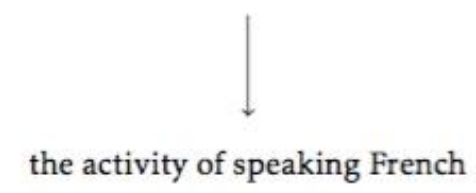

The resulting structure of the capacity (to learn) to speak French is illustrated in Figure 2. The vertical arrows represent actualization, where each item is actualized in the items (if any) below it (toward which the arrow points), and so is an actualization of the items (if any) above it (away from which the arrow points). As I've indicated, the whole capacity can be described as the capacity (to learn) to speak French. The capacity to speak French-which appears in the middle-is thus both the actualization of the capacity to learn French and itself a capacity that is actualized in the activity of speaking French. It is thus sometimes said to be the first actualization of the whole two-tiered capacity, the capacity (to learn) to speak French. Similarly, the activity of speaking French is said to be the second actualization of the whole two-tiered capacity. 


\section{Figure 3: the structure of a two-tiered capacity}

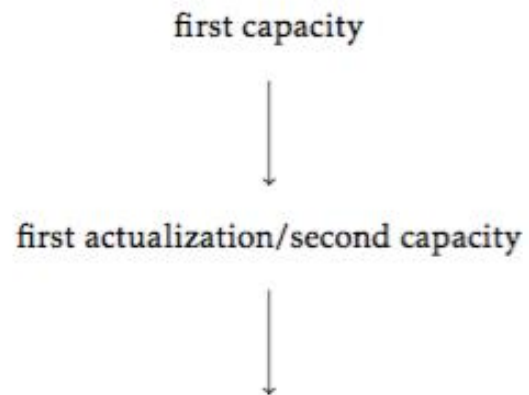

second actualization

Generalizing, then, the result is that a two-tiered capacity has a tripartite structure: first capacity $\rightarrow$ first actualization/second capacity $\rightarrow$ second actualization. In the case of the capacity to speak French, this structure is of course: capacity to learn French $\rightarrow$ capacity to speak French $\rightarrow$ activity of speaking French. The general structure, then, can be illustrated as in Figure 3. The whole two-tiered capacity is here shown to be composed of two capacities (first and second) the second of which is the actualization of the first - as is clear from the case of the capacity (to learn) to speak French: to have learned French is to be capable of speaking it.

For my purposes here, the crucial point about such a twotiered capacity is that its first actualization is both an actualization of a capacity (more precisely, it is the actualization both of the first capacity and of the whole twotiered capacity, though in different senses) and, because it is itself a capacity, a state. Put differently, the first actualization of a two-tiered capacity of this kind is, quite simply, an acquired disposition - where a disposition is, of course, a certain kind of state. 


\subsection{BELIEF AS A FIRST ACTUALIZATION OF ITS SUBJECT'S RATIONAL CAPACITIES}

My claim, then, is that belief is the first actualization/second capacity of its subject's rational capacities-which are therefore two-tiered. In order to make sense of this idea, however, we need to know both (i) precisely what two-tiered capacity belief is the actualization of and (ii) what belief is itself actualized in. In a certain sense, I've already implicitly answered the first question: belief is the actualization of its subject's rational capacities. But, as the second question reveals, in order to know what this means, we need to say what those rational capacities are capacities to do.

Here, though, I think there's an appealing answer: rational capacities are actualized in reasoning, i.e., in rational processes (e.g., intentional actions like walking across the street), activities (e.g., taking a stroll), and acts (e.g., inferring). One thing that these rational events all have in common is that they involve belief-as is revealed in the fact that they can all be (and normally are) explained (at least in part) by appeal to belief: you walk across the street because you believe that the store is on the other side; you take a stroll because you believe that it will improve your health; you come to believe (i.e., you draw the conclusion) that $p$ because you believe both that $q$ and that $r$. So, plausibly, all of these events either are or at least involve the actualization of a belief (conceived, of course, as a dispositional state). To have any given belief is thus to have the capacity (or the disposition, or the power) to, as I'll put it, execute certain rational events.

At the same time, however, a belief is itself an actualization (or-to borrow a Kantian term-a determination) of its subject's rational capacities. For there is an important difference between, for example, believing that the store is on the other side of the street and believing that taking a stroll will improve your health. And this difference 
is roughly analogous to that between knowing French and knowing German, which are, of course, different first actualizations (or determinations) of the capacity (to learn) to speak (a language). We might thus say that a subject's rational capacities are her capacities to execute rational events. The (or a) first actualization (/second capacity) of these capacities is an acquired belief-just as the first actualization of the capacity (to learn) to speak (a language) is an acquired language, or an acquired capacity (disposition, power) to speak it. Those beliefs can then themselves be actualized in the execution of rational events - which events thus count as second actualizations of the original rational capacities.

The basic idea, then-to spell it out just a bit more fully-is that the faculty of reason is a complex of capacities that is made up, at least in part, of tiered capacities of the sort illustrated by the capacity (to learn) to speak French. Belief, for its part, is the first actualization/second capacity of some of these tiered capacities. As such, it is both an actualization of its subject's rational capacities-her faculty of reason-and a state. It is, in other words, an acquired disposition (or power) to execute rational events.

Obviously, this basic idea needs to be spelled out in a complete theory of belief. If it can, though, the resulting theory will be one on which belief is both a state and an act of reason-both a state and an actualization of its subject's rational capacities. Perhaps that won't be enough to satisfy those who doubt that belief is a state. But, as I argued in sections $2-4$, it may be that what they want is something we just can't have. If it is, I hope that my proposal might offer at least some consolation. 


\section{REFERENCES}

BOyle, M. Active belief. Canadian Journal of Philosophy, Supplementary Volume 35: 119-47, 2009.

'Making up your mind' and the activity of reason. Philosophers' Imprint 11(17), 2011.

Die Spontaneität des Verstandes bei Kant und einigen Neokantianern. Deutsche Zeitschrift für Philosophie 63(4): 705-726, 2015.

Broome, J. Rationality Through Reasoning. Oxford: WileyBlackwell, 2013.

Cassam, Q. Judging, believing, and thinking. Philosophical Issues 20: 80-95, 2010.

Comrie, B. Aspect. Cambridge: Cambridge University Press, 1976.

Hieronymi, P. Controlling attitudes. Pacific Philosophical Quarterly 87(1): 45-74, 2006.

Two kinds of agency. In O'Brien and Soteriou 2009: 138-162, 2009.

KenNy, A. Action, Emotion, and Will. New York: Routledge \& Kegan Paul, 1963.

KorsgandD, C. The activity of reason. Proceedings and Addresses of the American Philosophical Association 83(2): 23-43, 2009.

Kosman, A. The Activity of Being. Cambridge, MA: Harvard University Press, 2013.

KOZIOLEK, N. Inferring as a way of knowing. Synthese. url: doi.org/10.1007/s11229-017-1632-4, 2017.

MS. Belief as the power to judge. 
LEE, W. Reasoning, rational requirements, and occurrent attitudes. European Journal of Philosophy. url: https://doi.org/ 10.1111/ejop.12342, 2018.

MCHugh, C. Judging as a non-voluntary action. Philosophical Studies 152: 245-269, 2011.

Epistemic responsibility and doxastic agency. Philosophical Issues 23: 132-157. 2013.

Mourelatos, A. P. D. Events, processes, and states. Linguistics and Philosophy 2: 415-434, 1978.

O'Brien, L. and Soteriou, M. (editors). Mental Actions. Oxford: Oxford University Press, 2009.

O'Shaughnessy, B. Consciousness and the World. Oxford: Clarendon Press, 200.

Owens, D. Reason Without Freedom: The Problem of Epistemic Normativity. Oxford: Routledge, 2000.

PeAcocke, C. Conscious attitudes, attention, and selfknowledge. In Wright, Smith, and Macdonald 1998.

RÖDL, S. Self-Consciousness. Cambridge, MA: Harvard University Press, 2007.

Self-Consciousness and Objectivity: An Introduction to Absolute Idealism. Cambridge, MA: Harvard University Press, 2018.

RYLE, G. The Concept of Mind. Edited by Daniel C. Dennett. Chicago: The University of Chicago Press, 2000, 1949.

SHah, N. and Velleman, J. DAvid. Doxastic deliberation. The Philosophical Review 114(4): 497-534, 2005.

SHOEMAKER, S. Self-intimation and second order belief. Erkenntnis 71: 35-51, 2009. 
SOTERIOU, M. Mental action and the epistemology of mind. Noûs 39(1): 83-105, 2005.

STEWARD, H. The Ontology of Mind: Events, Processes, and States. Oxford: Oxford University Press, 1997.

TORIBIO, J. What we do when we judge. Dialectica 65(3): 345367, 2011.

Vendler, Z. Verbs and times. Philosophical Review 56: 143 60, 2011.

Williamson, T. Knowledge and its Limits. Oxford: Oxford University Press, 2000.

Wright, C., SMith, Barry C. AND Macdonald, C. (editors). Knowing Our Own Minds. Oxford: Clarendon Press, 1998.

\section{(cc) $\mathrm{BY}$}

